\title{
Extreme Storm Surge estimation and projection through the Metastatistical Extreme Value Distribution
}

\author{
Maria Francesca Caruso ${ }^{1}$ and Marco Marani ${ }^{1}$ \\ ${ }^{1}$ Department of Civil, Architectural, and Environmental Engineering, University of Padova, 35131, Padova, Italy \\ Correspondence: Caruso, M.F. (mariafrancesca.caruso@phd.unipd.it)
}

\begin{abstract}
Accurate estimates of the probability of extreme sea levels are pivotal for assessing risk and the design of coastal defense structures. This probability is typically estimated by modelling observed sea-level records using one of a few statistical approaches. In this study we comparatively apply the Generalized Extreme Value (GEV) distribution, based on Block Maxima (BM) and Peak-Over-Threshold (POT) formulations, and the recently Metastatistical Extreme Value Distribution (MEVD) to

5 four long time series of sea-level observations distributed along European coastlines. A cross-validation approach, dividing available data in separate calibration and test sub-samples, is used to compare their performances in high-quantile estimation. To address the limitations posed by the length of the observational time series, we quantify the estimation uncertainty associated with different calibration sample sizes, from 5 to 30 years. Focusing on events with a high return period, we find that the GEV-based approaches and MEVD perform similarly when considering short samples (5 years), while the MEVD estimates outperform the traditional methods when longer calibration sample sizes (10-30 years) are considered. We then investigate the influence of sea-level rise through 2100 on storm surges frequencies. The projections indicate an increase in the height of storm surges for a fixed return period that are spatially heterogeneous across the coastal locations explored.
\end{abstract}

\section{Introduction}

The statistical analysis of extreme values of random variables is of wide conceptual and applicative importance in science and engineering (Coles, 2001; Beirlant et al., 2004; Castillo et al., 2005; Finkenstädt and Rootzén, 2004). Modelling extreme value probability of occurrence is indeed an active field of theoretical and applied research in many fields, such as hydrology and climatology (Katz et al., 2002), ecology (Katz et al., 2005), ocean wave modelling (Rueda et al., 2016; Benetazzo et al., 2017; Barbariol et al., 2019), transport engineering (Songchitruksa and Tarko, 2006), geophysical processes (Pisarenko et al., 2014a, b; Hosseini et al., 2020), biomedical data analysis (De Zea Bermudez and Mendes, 2012; Chiu et al., 2018), insurance and financial applications (Embrechts et al., 1997), and many others.

In particular, the reliable estimation of the occurrence probability of coastal flooding events of large magnitude is crucial to environmental hazard evaluation (Coles and Tawn, 2005; Hamdi et al., 2018) and to decision-making and mitigation measure design. In fact, coastal flooding hazard has been increasing at the global scale in recent decades, a trend expected to continue as a result of climate change (Meehl et al., 2007; Church et al., 2013; Fortunato et al., 2016). Several studies highlight that global sea-level rise will continue accelerating in the $21^{\text {st }}$ century as a consequence of climate change (Church and White, 2006; 
https://doi.org/10.5194/nhess-2021-236

Natural Hazards

Preprint. Discussion started: 18 August 2021

(c) Author(s) 2021. CC BY 4.0 License.

Jevrejeva et al., 2008; Church and White, 2011; Haigh et al., 2014b; Hay et al., 2015). Additionally, changes in storminess may have an important role in modifying the frequency and magnitude of water level extremes (Lowe et al., 2010; Menéndez and Woodworth, 2010; Woodworth et al., 2011). Much of the current work on extreme coastal flooding events is based on the classical Extreme Value Theory (EVT) (Fréchet, 1927; Gumbel, 1935, 1958; Gnedenko, 1943; Chow, 1953; Dalrymple, 1960; Pickands, 1975; Hosking and Wallis, 1987, 1993, 1997; Coles, 2001; Woodworth and Blackman, 2002; Hamdi et al., 2014, 2015), which identifies the family of distribution functions known as Generalized Extreme Value (GEV) distribution (Von Mises, 1936) as a general model for the distribution of maxima (or minima) extracted from fixed time periods of equal length ("blocks", most commonly with length of one year). The GEV, according to its original formulation, arises as a limiting distribution for maxima (or minima, not considered here) of a sequence of independent and identically distributed (i.i.d.) random variables. The Peak-Over-Threshold (POT) formulation (Balkema and de Haan, 1974; Pickands, 1975), extends the original GEV derivation by modelling all events exceeding a high threshold, as opposed to considering just yearly maxima as in the GEV-Block Maxima formulation (GEV-BM). The POT approach again recovers the GEV distribution as the distribution of the annual maxima if two assumptions are valid (Davison and Smith, 1990): 1) the number of events/year is Poisson-distributed; 2) exceedances over the threshold come from a Generalized Pareto Distribution (GPD). For a brief overview of the theory underlying EVT and POT method the reader can refer to supplementary material. The GEV-POT approach is often considered to be superior to GEV-BM in practical applications, due to its more efficient use of often scarce observations. For extreme sealevel studies in particular, Coles and Tawn (2005) and Haigh et al. (2010) recognize two weakness in the use of the GEV-BM analysis: 1) sea level is the combination of tide-driven (deterministic) and storm-driven (stochastic) components. The presence of a deterministic component is suggested to violate the i.i.d. assumption required in the GEV-BM derivation; 2) sea-level data are collected frequently (e.g., hourly), while the GEV-BM approach only studies annual maxima, with an extremely inefficient use of the data. The POT framework exploits more of the available information with respect to the BM approach (e.g., Coles, 2001; Bernardara et al., 2014). However, the choice of a suitable threshold to retain a few above-threshold events/year is a critical step, and the estimation uncertainty significantly depends on threshold selection (Önöz and Bayazit, 2001; Li et al., 2012). The selected threshold value implies a balance between bias and estimation error variance (Coles, 2001). In fact, too low a threshold will violate the independence hypothesis of the framework, leading to bias, while too high a threshold will retain just a few values above the threshold, leading to high error variance.

More generally, GEV-based approaches, by construction, discard most of the observations, and do not attempt to optimize the use of the available information (Volpi et al., 2019). Furthermore, the traditional extreme value theory derives the GEV distribution either as the asymptotic distribution when the number of events/block becomes very large, or through the ad-hoc GPD-Poisson assumptions underlying the POT approach. Whether these hypotheses do apply to the case of storm surges is a matter of discussion, but it seems beneficial to adopt methods that require the least amount of a-priori assumptions. As a contribution to overcoming the limitations of the traditional EVT, here we explore the use of an alternative approach for modelling extreme sea levels, the Metastatistical Extreme Value Distribution (MEVD). This approach was introduced by Marani and Ignaccolo (2015) and has been previously applied to rainfall, flood-frequency analysis, and hurricane intensities. The MEVD models the distribution of yearly maxima starting from the distribution of "ordinary values", i.e. all the available data, in con- 
trast to just considering annual maxima or a few values above a threshold. In previous applications, the MEVD has been shown to significantly reduce estimation uncertainty compared to traditional approaches, especially when considering return periods greater than the sample size used for parameter estimation (Zorzetto et al., 2016; Marra et al., 2018; Miniussi and Marani, 2020; Miniussi et al., 2020a, b).

Here we comparatively analyze the performance of GEV-based approaches and of the MEVD in high-quantile estimations with application to extreme sea levels at different observation sites. The aim is to: 1) identify the statistical tool affording minimal uncertainty in the estimate of extreme sea levels with assigned probability of exceedance, and 2) model and understand how climate change will affect the extreme sea-level occurrence. To achieve these objectives, we analyze selected sea level time series along the European coastline and evaluate extreme sea level predictive uncertainty by adopting a cross-validation approach, in which calibration and test samples are kept separate and independent. Subsequently, we use the optimized estimation method to infer possible changes in coastal flooding hazard under IPCC climate change scenario RCP4.5 and RCP8.5.

The structure of the paper is as follows: Section 2 outlines the sea-level data and the methodology used in this application, results are described in Section 3, while the conclusions are given in Section 4.

\section{Materials and Methods}

\subsection{Data}

The analyses were performed using daily and hourly sea-level records from four tide gauge stations (see Table 1) distributed along European coastlines: Venice (Italy), Hornbæk (Denmark), Marseille (France), and Newlyn (United Kingdom). The study sites span a variety of geographical locations, coastal morphologies and storm regimes.

Venice sea-level data (maximum and minimum daily observations) were obtained from the "Centro Previsioni e Segnalazioni Maree" of the Venice Municipality (https://www.comune.venezia.it/it/content/centro-previsioni-e-segnalazioni-maree) for the Punta della Salute gauge station. The remaining water level data, all at the hourly scale, were downloaded from the University of Hawaii Sea Level Center (UHSLC) repository (http://uhslc.soest.hawaii.edu/data/?rq\#uh745a/).

All sea-level datasets span long observational periods: 148 years for Venice, 122 years for Hornbæk, 115 years for Marseille (ca. 19 missing years) and 102 years for Newlyn.

85 The raw data for all stations were pre-processed to eliminate: 1) years with less than six months of water level observations, and 2) days with less than $24 \mathrm{~h}$ of data (for the case of hourly data). This process yields four "cleaned up" time series that were subsequently used in the analyses (see Table 1). Figure 1 shows daily maximum sea levels at the gauge stations explored after pre-processing. 
https://doi.org/10.5194/nhess-2021-236

Preprint. Discussion started: 18 August 2021

(c) Author(s) 2021. CC BY 4.0 License.

Table 1. Information of sea-level data used in this application.

\begin{tabular}{|c|c|c|c|c|c|c|c|}
\hline \multirow{2}{*}{ Site name } & \multirow{2}{*}{ Country } & \multicolumn{2}{|c|}{ Location (degree, min.) } & \multirow{2}{*}{ Period } & \multirow{2}{*}{$\begin{array}{l}\text { Missing } \\
\text { years (\%) }\end{array}$} & \multirow{2}{*}{$\begin{array}{l}\text { Deleted } \\
\text { years }\end{array}$} & \multirow{2}{*}{$\begin{array}{l}\text { Number } \\
\text { of years }\end{array}$} \\
\hline & & Lat. & Long. & & & & \\
\hline Venice & Italy & $45^{\circ} 25.0^{\prime} \mathrm{N}$ & $12^{\circ} 20.0^{\prime} \mathrm{E}$ & $1872-2019$ & - & - & 148 \\
\hline Hornbæk & Denmark & $56^{\circ} 06.0^{\prime} \mathrm{N}$ & $12^{\circ} 28.0^{\prime} \mathrm{E}$ & $1891-2012$ & - & 1985 & 121 \\
\hline Marseille & France & $43^{\circ} 16.7^{\prime} \mathrm{N}$ & $5^{\circ} 21.2^{\prime} \mathrm{E}$ & $1885-2018$ & 14.2 & $\begin{array}{l}1897 ; 1918 ; \\
1919 ; 1928 ; \\
1937 ; 1940 ; \\
1998 ; 2009 ; \\
2010\end{array}$ & 106 \\
\hline Newlyn & $\begin{array}{l}\text { United } \\
\text { Kingdom }\end{array}$ & $50^{\circ} 06.1^{\prime} \mathrm{N}$ & $5^{\circ} 32.5^{\prime} \mathrm{W}$ & $1915-2016$ & - & $1984 ; 2010$ & 100 \\
\hline
\end{tabular}

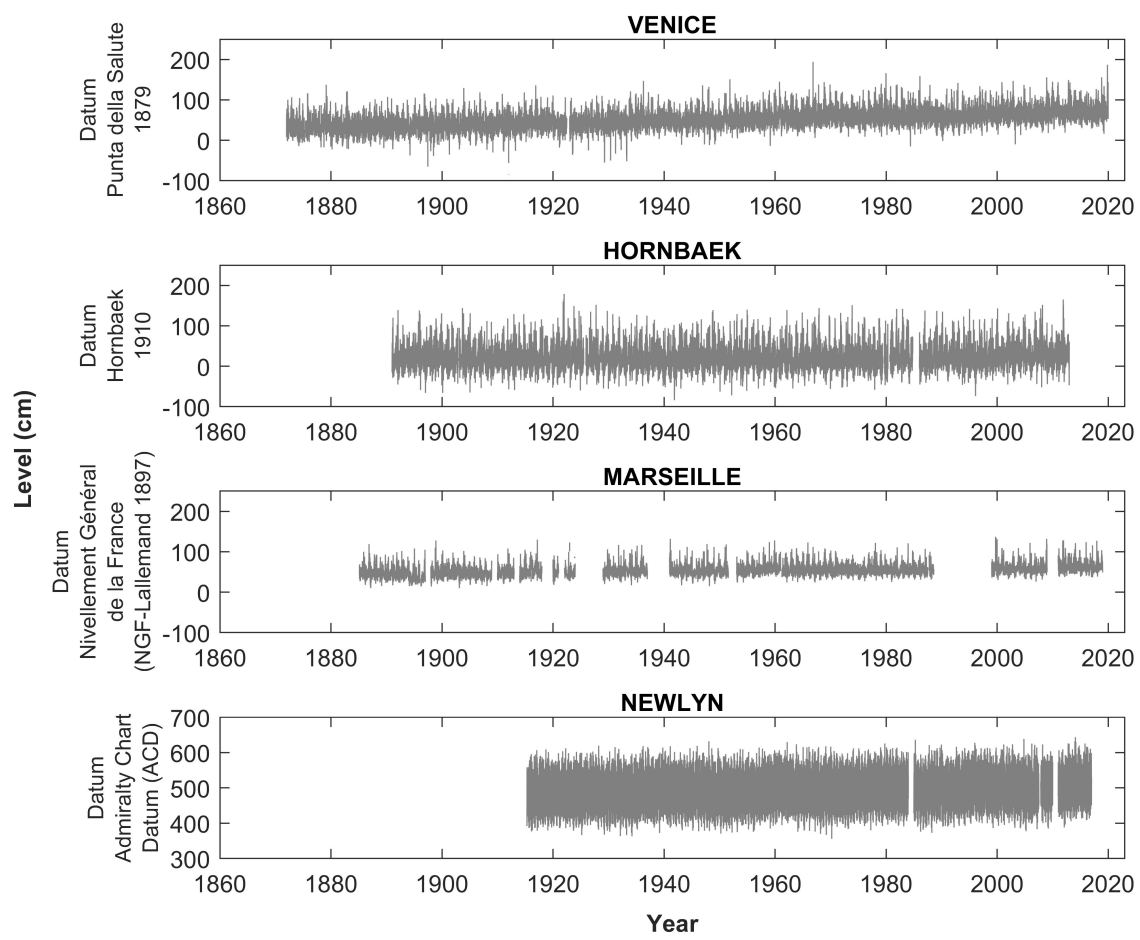

Figure 1. Daily maximum sea levels at different gauge stations explored after pre-processing: Venice (IT), Hornbæk (DK), Marseille (FR), and Newlyn (UK). 


\subsection{Methods}

\subsubsection{The Metastatistical Extreme Value Distribution}

The typical EVT derivation starts from the premise that the maximum value among $n$ realizations of a random variable is distributed according to the cumulative distribution function $P(X \leq x)=G(x)=F(x ; \vec{\theta})^{n}$ (where, as customary, a capital letter indicates the random variable and a small cap letter indicates a value of the random variable). This approach assumes that the $n$ values of the random variable of interest are generated by the same distribution, the "ordinary value" distribution $F(x ; \vec{\theta})$, and are thus independent and identically distributed. $n$ is the number of events in a block, such that $G(x)$ is the cumulative distribution of the block maxima. The classical EVT assumes that either the number of events/year is large (asymptotic hypothesis, leading to the GEV-BM formulation) or that the number of events/year above a high threshold is distributed according to a Poisson distribution (GEV-POT formulation). The recently-proposed Metastatistical Extreme Value Distribution (Marani and Ignaccolo, 2015) relaxes these hypotheses by considering both the parameters $(\vec{\theta})$ of the ordinary value probability distribution and the number of events/year to be random variables. The MEVD cumulative distribution of block maxima is then defined as the compound probability:

$G(x)=\sum_{n=1}^{+\infty} \int_{\Omega_{\vec{\Theta}}} F(x ; \vec{\theta})^{n} g(n, \vec{\theta}) d \vec{\theta}$

where $g(n, \vec{\theta})$ is the joint probability distribution of the number of events in a year and of the parameters vector (discrete in $N$ and continuous in $\vec{\Theta}), \Omega_{\vec{\Theta}}$ is the population of all possible parameter values.

For practical applications, the MEVD can be approximated by substituting ensemble average in Eq. 1 with the sample average computed over all the blocks in the time series, obtaining:

$G(x) \cong \frac{1}{M} \sum_{j=1}^{M} F\left(x ; \theta_{j}\right)^{n_{j}}$

where $M$ is the number of blocks in the historical record, $F\left(x ; \overrightarrow{\theta_{j}}\right)$ is the cumulative distribution of ordinary values in the $j^{t h}$ year, and $n_{j}$ is the number of events in the $j^{t h}$ year. A common choice for the block length is 1 year. Note that the values of the parameters $\overrightarrow{\theta_{j}}$ may be estimated on Estimation Windows (EW) with length that is different from block length. For example, if the block length is 1 year, it may be advantageous to estimate parameter values on longer time slices to ensure, depending on the rate of event occurrence, that a reliable estimation of the parameters is possible. Miniussi and Marani (2020) in applications to daily rainfall extremes find that, when the number of events per year is less than 20-25 events/years, then the optimal EW length may be greater than one year.

MEVD has been applied in several earth-science contexts. In rainfall extremes estimates, the ordinary value distribution is assumed to be Weibull when applied to point daily rainfall (Marani and Ignaccolo, 2015; Zorzetto et al., 2016; Schellander et al., 2019; Miniussi and Marani, 2020; Miniussi et al., 2020b), point sub-daily rainfall (Marra et al., 2018), and satellite rainfall estimates (Zorzetto and Marani, 2019, 2020). For flood across the United States, Miniussi et al. (2020a) propose to adopt 
a Gamma distribution for $F\left(x ; \overrightarrow{\theta_{j}}\right)$. Hosseini et al. (2020) describe Atlantic hurricane intensities using a Generalized Pareto ordinary value distribution. In all cases the appropriate form for the underlying ordinary value distribution was identified by minimizing the estimation uncertainty within a cross-validation approach, which is also followed here. In the present context, we define as ordinary values any storm-surge water elevation (i.e. the maximum water level reached during a storm event) greater than a site-specific threshold value. This threshold is chosen to be as small as possible (differently from the POT approach), to retain as much of the observational information as possible, and will be dependent on the magnitudes of the tidal and storm contributions.

As suggested by several rainfall applications, ordinary distribution parameters are here estimated using the Probability Weighted Moments (PWMs) method in non-overlapping estimation windows of 5 years. PWM estimation, introduced by Greenwood et al. (1979), is widely applied because of its good performance, particularly in the presence of small sample sizes, its reduced estimation bias and sensitivity to the presence of outliers in the data (Hosking et al., 1985; Hosking and Wallis, 1987; Hosking, 1990).

\subsubsection{Mean sea level removal}

The sea-level sequence is highly correlated and is generated by a non-stationary process due to long term trends in mean sea level, the deterministic tidal component, surge seasonality, and interactions between the tide and surge (Dixon and Tawn, 1999). Tide-surge interactions may change amplitude and phase of the surges, mostly in shallow estuarine areas (Johns and Ali, 1980; Bernier and Thompson, 2007; Zhang et al., 2010). However, in deeper sea conditions the non-linear interactions between tide and surge have been found to be negligible (Lionello et al., 2006). Hence, we will neglect this effect here and will consider the observed sea level as the sum of additive components. Under this premise, for a given site and at any instant of time $t$, the observed sea level $z(t)$ (after averaging out waves), can be split into three components (Pugh and Vassie, 1979): mean sea level, $m s l(t)$, astronomically induced tidal level, $x(t)$, and meteorologically induced surge level, $y(t)$ :

$z(t)=m s l(t)+x(t)+y(t)$

$m s l(t)$ represents the long-term variations of water levels and of the elevation datum (i.e. possible land subsidence or uplift). Local $m s l(t)$ does not change uniformly over time and its calculation is affected by many factors, such as tidal phases, long-term wind and atmospheric pressure patterns, vertical land motion (subsidence or uplift). The tidal contribution to the instantaneous sea level, $x(t)$, caused by the gravitational forces exerted by the moon and the sun is deterministic in nature, and can be predicted with a good degree of accuracy. This tidal variability occurs with characteristic periodicities between 12 hours and 18.61 years (Eliot, 2010; Haigh et al., 2011; Pugh and Woodworth, 2014; Peng et al., 2019; Valle-Levinson et al., 2021). This latter longest tidal periodicity corresponds to the precession of the lunar nodal cycle. The storm-surge contribution, $y(t)$, is the meteorologically-induced change in the water level generated by a combination of factors, such as the magnitude and direction of the wind, spatial gradients in atmospheric pressure, storm size, fetch, bathymetry, storm duration, etc (Hall and Sobel, 2013).

Two classes of methods are widely used to estimate the probability of occurrence of extreme sea levels: direct and indirect meth- 
ods. Indirect methods model separately the deterministic and the stochastic components of $z(t)$. A direct method is adopted here, in which we study the distribution of the sum, $h(t)$, of the contributions from the deterministic tide and the stochastic surge:

$h(t)=z(t)-m s l(t)$

From a statistical point of view, this choice is justified by the fact that the random arrival of storms adds a stochastic surge contribution at unpredictable times, thereby causing $h(t)$ to be values from a random variable, even though it contains a deterministic component. The presence of a deterministic component of course does imply a strong auto-correlation in the observed signal, which will be subsequently filtered out by suitable signal processing described below.

$m s l(t)$, is here computed as the yearly average of daily levels. The yearly average is chosen, rather than the customary 19-year average that eliminates all tidal periodicities, however small in amplitude, to better capture the surge contribution that causes the water level to deviate during a storm with respect to the "current", yearly, value of $m s l(t)$. Once $h(t)$ is computed by removing $m s l(t)$ from recorded levels, all local maxima of $h(t)$, or water level peaks, are identified and their values constitute the basis for subsequent analyses.

\subsubsection{Selection of independent events}

The GEV-based approaches are fit on either annual peak maxima (GEV-BM) or on a few water level peaks over a high threshold (GEV-POT), which can be assumed to be realizations of independent stochastic variables. The MEVD requires that all ordinary values (level peaks in this case) within one block may be assumed to be realizations from independent random variables. This hypothesis, in turn, requires that observed peaks are filtered to only retain events that may be considered to be independent, through a de-clustering process (Coles, 2001; Ferro and Segers, 2003; Beirlant et al., 2004; Bommier, 2014; Marra et al., 2018). Several criteria have been developed for such processing of the data. A common criterion sets the minimal time separation, or lag $(\tau)$, for two events to be considered independent. Intuitively, high water-level events separated by a sufficiently long time period are reasonably caused by distinct storm events. However, when analyzing the water level with respect to current mean sea level, a quantity that contains the deterministic tidal contribution, dependence may be expected to be present also for large lags. In theory, some dependence is present for lags up to the longest periodicity in the tidal signal (18.61 years). In practice, as the dependence in the tidal signal decreases for increasing lag, one expects that a much shorter threshold time lag will be sufficient to make sure that only independent events are considered (Figure S1). For example, the independence between two consecutive storm surge events in southern Europe has been found to be achieved with a threshold lag of 3 days (Cid et al., 2015). A threshold separation of one day between consecutive events is imposed by Tebaldi et al. (2012) in their analysis of storm surges along the US coast. Haigh et al. (2010) adopted a threshold lag of $30 \mathrm{~h}$ in the English Channel, while Bernardara et al. (2011) adopted a $72 \mathrm{~h}$ independence criterion. After exploring values between $24 \mathrm{~h}$ and several days, we adopted a threshold lag of 30 days, which yielded the minimum estimation error under the MEVD approach, and is consistent with the main lunar periodicity. The result of this declustering process is a set of independent events with magnitudes $h_{k}$, whose number $n_{j}$ in year - or block - $j$ is a realization of a random variable as illustrated in Eq.s 1 and 2. 


\subsubsection{Cross-validation procedure}

Statistical modelling aims to use sample information to infer the probability distribution of the population from which the data are extracted. This inference is uncertain due to imperfect parameter estimates and to the possible inability of the chosen distribution to capture the statistical properties of the underlying population. Although these sources of uncertainty are inherent in any statistical model, their impact can be minimized by a careful choice of the model and by an effective use of all sources of information (Coles, 2001). In many applications uncertainty is estimated by means of goodness-of-fit measures, which quantify how well the distribution compares to the sample on which it was fitted. However, this procedure does not provide a measure of the predictive uncertainty encountered when trying to estimate the probability of occurrence of the "next", yet unobserved value. In this study, we evaluate the performance in high-quantile estimation associated with the use of the MEVD and the GEV distribution, by means of a cross-validation (CV) procedure, in which model predictions of the probability of occurrence are compared to frequencies from data that were not used in the estimation of model parameters. This is possible by dividing observations into two sets of independent data: the estimation set is the sample from which model parameters are estimated and the test set is the sample with which model predictions are compared.

The procedure can be summarized as follows: a) we randomly reshuffle the observational years on record while keeping all the water level independent peaks in their original year to 1) preserve both the ordinary value frequency distribution in each year and the distribution of the number of events/year, and 2) remove possible non-stationarity and correlation in the time series; b) we divide the observational sample into two independent sub-samples obtained by randomly selecting $S$ years from the original time series of length $M$ : this sub-sample (in the following "calibration sample") is used for parameter estimation, while data in the remaining $V=M-S$ years are used for testing (validation sample); c) we estimate the GEV and MEVD quantiles using the parameter values estimated in step b) from the calibration sub-sample; d) in every realization (for $p=1, \ldots, N r$; $N r=1000$ here) and for a fixed mean recurrence time ( $T r)$, we compute the Non Dimensional Error between the estimated and observed quantiles as follows: $N D E_{p}(S, T r)=\left[h_{(e s t, p)}(S, T r)-h_{(o b s, p)}(S, T r)\right] / h_{(o b s, p)}(S, T r)$; e) we repeat the CV scheme above $N r$ times. This procedure is performed for different calibration sample sizes $(S=5,10,20$, and 30 years) to evaluate how estimation uncertainty varies with return period and calibration sample size.

\subsubsection{Future storm-surge projections}

Future increases in the frequency of intense storm surges due to climate change will have serious impacts on coastal regions. These impacts will vary temporally and regionally, depending on the local mean sea-level rise (including possible subsidence or uplift), current storm-surge intensity probability distributions, changes in the dominant meteorological dynamics. In this particular application to extreme storm surges, only the first two factors are considered.

210 It is very likely that sea-level rise will continue to accelerate over time, thereby increasing the frequency of extreme sea level events, leading to severe flooding in many low-lying coastal cities and small islands (Oppenheimer et al., 2019). As Haigh et al. (2011) underline, changes in mean sea level have an effect on extreme sea levels in two ways: (i) directly: a rise (or fall) in mean sea level will result in a lower (or higher) surge elevation at high tide being necessary to produce a sea level high enough 
to cause flooding; (ii) indirectly: changes in mean sea level alter water depths. Several authors (Zhang et al., 2000; Woodworth

and Blackman, 2004) have found that past variations in extreme sea levels have been primarily determined by changes in mean sea level. This suggests that indirect effects and variations in storminess have been small, in the observational record, compared with the direct effects (Haigh et al., 2014a). We thus focus on the latter here.

Various techniques have been used to study possible changes in coastal flooding hazard (e.g., McInnes et al., 2013; Vousdoukas et al., 2016). In this application, the probability of future storm surges along European coastlines are estimated by assuming that the tidal and storm-surge components, computed with respect to the current mean sea level, do not change as mean sea-level changes. Hence, we do not include the effects of possible changes in local "storminess", a widely utilized approach (Araújo and Pugh, 2008; Haigh et al., 2010; Tebaldi et al., 2012).

To assess how the exceedance probabilities of extreme water levels might change in the future, the projections of sea-level rise through 2100 from the IPCC's Fifth Assessment Report (AR5) are used. In particular, we explore an intermediate (RCP4.5) and an extreme scenario (RCP8.5), using CMIP5 model outputs from the "Integrated Climate Data Center" (ICDC) database (University of Hamburg: https://icdc.cen.uni-hamburg.de/en/ar5-slr.html).

For each tide gauge, our approach can be summarized as follows: 1) we infer the probability distribution of extreme water levels (annual maxima) from observed independent surge events whose intensity (maximum water level attained, $h_{k}$ ) is defined with respect to the concurrent mean sea level computed on a yearly basis; 2) we estimate the future probability of extreme sea levels by translating extreme level quantile estimates upward according to the projected mean sea level at each location (thereby implicitly assuming subsidence/uplift to be negligible).

\subsubsection{Return period}

One of the main objectives of frequency analysis is to calculate the average recurrence interval or return period. It is a widely used concept in hydrological and geophysical risk analysis. If a process is stationary, the return period $(\mathrm{Tr})$ of an event magnitude is defined as the average time elapsing between two consecutive exceedances of this magnitude. Alternatively, it may be said that a magnitude value is expected to be exceeded, on average, in each return period. If the yearly-maximum magnitude $h$ is exceeded on average once in $\operatorname{Tr}$-years, then its exceedance probability, $E(h)=1-G(h)$, in a given year is:

$E(h)=P(H \geq h)=\frac{1}{\operatorname{Tr}(h)}$

Therefore, the return period of the level value $h$ is the inverse of the probability of exceedance and can be expressed as a function of the cumulative distribution, $G(h)$, of annual maxima, e.g. through the MEVD:

$\operatorname{Tr}(h)=\frac{1}{E(h)}=\frac{1}{1-G(h)}$

Because there is a one-to-one relation between the value of the sum of the astronomical and the storm surge contribution, $h$, and the total sea level, $z=h+m s l$, one can write $P(H>h)=P(H>z-m s l)=P(Z>z=h+m s l)$, such that Eq. 3 can be used, once the cumulative distribution is known, to determine the return period of the total sea level:

$\operatorname{Tr}(z)=\frac{1}{1-G(z-m s l)}$ 
https://doi.org/10.5194/nhess-2021-236

Based on the hypothesis introduced in $\S 2.2 .5$ that mean sea-level rise is the dominant effect in future coastal flooding, we assume that the characteristics of the extremes (i.e. the parameters of the GPDs defining the MEVD) remain valid in future scenarios. Eq. 4 clarifies that the return period of a fixed value $z$ decreases as $m s l$ increases, basically because for higher values of $m s l$ a smaller value of $y$ is needed to achieve the same total level $z$. This decrease is non-linear, due to the nonlinear form of the right-hand side in Eq. 4.

\section{Results and discussion}

\subsection{Trend analysis}

We start by computing mean sea level on yearly basis and by subtracting it from observed water level. The first question that we want explore is the presence of log-term trends in the observed time series. We compute the deviation of yearly maxima from yearly mean sea level and test the presence of trend by the two-tail Mann-Kendall test (Mann, 1945). Figure 2 summarizes results for each location explored. We apply a linear fit to the yearly deviations from the yearly mean sea level and obtain: a) Venice time series (1872-2019) have a slope of about $0.7 \mathrm{~mm} /$ year (p-value $=0.0141$ ); b) Hornbæk record (1891-2012) shows a trend of about $0.4 \mathrm{~mm} / \mathrm{year}$ ( $\mathrm{p}$-value $=0.3525)$; c) Marseille sea levels $(1985-2018$ ) have a linear trend with slope of about $-0.6 \mathrm{~mm} /$ year $(\mathrm{p}$-value $=0.1109)$; $)$ Newlyn time series $(1915-2016)$ display a slope of $0.05 \mathrm{~mm} /$ year $(\mathrm{p}$-value $=0.9976)$. The presence of a statistically significant trend is confirmed, with $95 \%$ confidence level, only for Venice gauge station. This result suggests that the increase of the yearly maximum deviations from yearly mean sea level is a direct result of the local morphological variations and/or vertical land motion (subsidence) that reduce the propagation and dissipation of the tide inside the Venice lagoon. Instead, for the other locations, the null hypothesis of no trend cannot rejected through a Mann-Kendall test with 5\% significance levels. In any case, the potentially confounding effect of the possible presence of trends is in our study avoided by the $\mathrm{CV}$ approach, which randomly reshuffles the sequence of observed years.

\subsection{Extreme value analysis}

The MEVD formulation requires the choice of an optimal distribution of ordinary values that can represent the characteristics of the natural phenomenon under analysis. Different candidate distributions for the $F\left(x ; \overrightarrow{\theta_{j}}\right)$ in Eq. 2 are evaluated and the most suitable distribution is selected on the basis of the $C V$ procedure comparing the MEVD-estimated quantiles with the observed ones. According to different tests, the appropriate distribution to model the ordinary sea-level values is the Generalized Pareto Distribution (GPD).

As mentioned above ( $\$ 2.2 .3$ ), the independence between two consecutive storm events is guaranteed by imposing a minimum time lag. Firstly, we select daily maxima sea levels from the original record; secondly, define as independent events those that are separated by at least 30 days. Subsequently, the samples used for statistical inference are built as follows: 1) GEV-BM: the yearly maxima are selected; 2) GEV-POT: as proposed by Coles (2001), the optimal threshold $(u)$ is determined by studying the stability of the GPD shape $(\xi)$ and modified scale $\left(\sigma^{*}=\sigma_{u}-\xi u\right)$ parameters estimated using a wide range of values of $u$. 

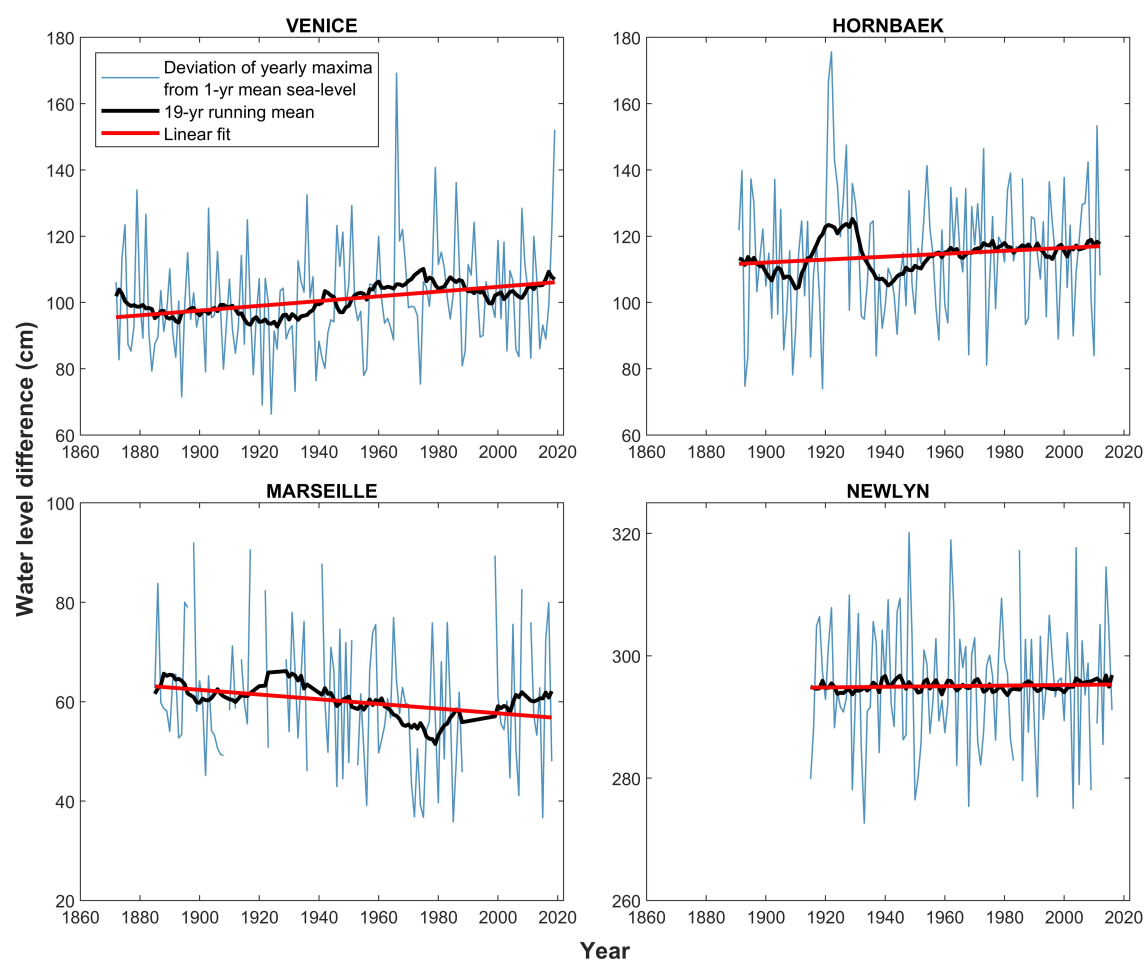

Figure 2. Deviation of yearly maxima from yearly mean sea level (blue line), 19-yr running mean (black line) and linear fit (red line) calculated for selected sites.

Using this method, the following threshold values were identified: $65 \mathrm{~cm}$ (Venice), $50 \mathrm{~cm}$ (Hornbæk), $35 \mathrm{~cm}$ (Marseille) and $260 \mathrm{~cm}$ (Newlyn); 3) MEVD: all the independent storm events above a low threshold are used to fit the probability distributions of ordinary values. These thresholds are set to be large enough to filter out water level peaks that are likely to be associated to conditions without any storm contribution and sufficiently low to maximize the amount of information used. Based on local tidal ranges, the low thresholds adopted at the four study sites are $59 \mathrm{~cm}$ for Venice, $40 \mathrm{~cm}$ for Hornbæk, $25 \mathrm{~cm}$ for Marseille, and $250 \mathrm{~cm}$ for Newlyn. For every observed site, Table 2 displays the gradual increase in the number of independent events used to infer the distributions when moving from GEV-BM, GEV-POT to MEVD approaches.

Considering the above threshold values, the observed and estimated distributions of storm surge are compared by plotting their quantiles against each other. By comparing measures of in-sample and out-of sample test predictive accuracy, the results are presented by means of quantile-quantile (QQ) plots in supplementary Figures S2, S3, S4, S5 and S6. QQ-plots are obtained as a result of the $\mathrm{CV}$ procedure with 1,000 random realizations and sample size: a) $S=30$ years (in-sample-test on the left column); b) $V=L-S$ years (out-of-sample test on the right column). The colours in the figures represent the density of points around the $45^{\circ}$ line (i.e. the line of equality). This highlights how the estimated quantiles are closely comparable with the observed ones for all the three approaches tested and for both the sample size explored ( $S$ and $V$ ). In particular, when out-of-sample 
performance is considered, MEVD proves to be a good model for the extreme sea levels.

Table 2. Total number of independent events and average number of events/year calculated for all observation sites.

\begin{tabular}{llccc}
\hline \multirow{2}{*}{ Site name } & \multicolumn{4}{c}{ Independent events } \\
\cline { 2 - 5 } & & BM & POT & MEVD \\
\hline \multirow{2}{*}{ Venice } & Total & 148 & 605 & 775 \\
& N. events/year & 1 & 4.08 & 5.23 \\
\hline \multirow{2}{*}{ Hornbæk } & Total & 121 & 595 & 736 \\
& N. events/year & 1 & 4.91 & 6.08 \\
\hline \multirow{2}{*}{ Marseille } & Total & 106 & 275 & 489 \\
& N. events/year & 1 & 2.57 & 4.61 \\
\hline \multirow{2}{*}{ Newlyn } & Total & 100 & 399 & 520 \\
& N. events/year & 1 & 3.99 & 5.20 \\
\hline
\end{tabular}

We now focus on evaluating the performance of the three approaches (GEV-BM, GEV-POT and MEVD) in high-quantile estimation. We explore the predictive performance of the MEVD and GEV distribution as a function of the NDE (\$2.2.4) computed for the maximum return period, $T r_{\max }=M-S+1$, associated with the maximum value in each test sub-samples that we randomly extract in the CV approach. The use of NDE metric allows to easily characterize and compare models estimation uncertainty associated with fixed return time of interest and the variation of the calibration sample size (from 5 to 30 years).

The results are summarized by means of box-plots (Figure 3) and kernel density estimates computed for a calibration sample size of 30 years (Figure 4). Table 3 summarizes the main results underlying the chosen evaluation metric. When we focus on the case of a short sample (5 years), different sites display variable results: I) the GEV and MEVD approaches perform similarly for Venice (Figure 3(a)) and Hornbæk (Figure 3(b)) with similar interquartile ranges and underestimations of the actual quantile; II) for the Newlyn gauge station (Figure 3(d)) the GEV-BM distribution yields better results, even though the POT and MEVD median error are also close to zero. On the contrary, when we consider longer calibration sample sizes (from 10 to 30 years), the MEVD-based estimates outperform the traditional approaches for most gauge stations explored: I) results for the Venice site confirm the robustness of the MEVD with respect to the GEV distribution especially for calibration sample size equal to 30 years. In this case, the median error in the MEVD estimates tends to be closer to zero (-0.004), corresponding to approximately unbiased estimates; II) the Hornbæk station displays similar results to those for Venice and the MEVD-based estimates become more reliable when we consider a calibration sample size greater than 10-20 years; III) Newlyn estimation errors show a trade-off between the BM method and MEVD for calibration sample size equal to 20 and 30 years.

Results for the Marseille site show a peculiar behaviour that requires a specific discussion. In this case, the application of the traditional extreme value theory is advantageous when compared with the MEVD (Figure 3(c)). In order to better understand the application to the Marseille site, we performed MEVD parameter estimation using two approaches: 1) estimation based on non-overlapping calibration samples of fixed size (5 years as for the other sites); 2) parameter estimation on data from the whole calibration sample. The comparison of the results from these two set-ups confirms that when longer time slices are used for estimating GPD parameters (black colour in Figure 3(c)), the MEVD performance is improved (for example when we 
https://doi.org/10.5194/nhess-2021-236

Preprint. Discussion started: 18 August 2021

(c) Author(s) 2021. CC BY 4.0 License.

\section{Table 3.}

Results of the evaluation metric obtained for all the gauge stations and for calibration sample sizes $(S)$ equal to 5 and 30 years. In the case of the Marseille site, text in bold refers to MEVD parameter estimation based on data from the whole calibration sample size.

\begin{tabular}{llrrrrrr}
\hline \multirow{2}{*}{ Site name } & \multirow{2}{*}{ Variables } & \multicolumn{3}{c}{$\mathrm{S}=5 \mathrm{yrs}$} & \multicolumn{3}{c}{$\mathrm{S}=30$ yrs } \\
\cline { 3 - 7 } Venice & NDE-median & -0.160 & -0.175 & -0.178 & -0.133 & -0.158 & -0.004 \\
& NDE-mean & -0.069 & -0.101 & -0.116 & -0.087 & -0.133 & -0.024 \\
& NDE-std & 0.366 & 0.274 & 0.267 & 0.156 & 0.113 & 0.155 \\
\hline \multirow{3}{*}{ Hornbæk } & NDE-median & -0.119 & -0.104 & -0.113 & -0.113 & -0.115 & 0.056 \\
& NDE-mean & -0.069 & -0.101 & -0.116 & -0.068 & -0.087 & 0.077 \\
& NDE-std & 0.366 & 0.274 & 0.267 & 0.113 & 0.100 & 0.131 \\
\hline \multirow{5}{*}{ Marseille } & NDE-median & -0.0003 & 0.059 & 0.172 & 0.016 & 0.047 & 0.357 \\
& NDE-mean & 0.045 & 0.129 & 0.262 & 0.013 & 0.050 & 0.374 \\
& NDE-std & 0.252 & 0.350 & 0.421 & 0.072 & 0.115 & $\mathbf{0 . 1 8 3}$ \\
& NDE-median & -0.010 & -0.030 & -0.033 & -0.033 & -0.032 & 0.0008 \\
\hline \multirow{3}{*}{ Newlyn } & NDE-mean & 0.003 & -0.022 & -0.026 & -0.002 & -0.031 & 0.0020 \\
& NDE-std & 0.050 & 0.042 & 0.042 & 0.016 & 0.014 & 0.0210 \\
\hline
\end{tabular}

consider $S=30$ years, MEVD median $\left[S-\right.$ year $\left.{ }_{\text {window }}\right]=0.17$ vs. MEVD median $\left[5-\right.$ year $\left.\left.r_{\text {window }}\right]=0.35\right)$, though it does not yet match the results obtained from GEV-BM approach $($ GEV-BM median error $=0.016$ ). This can be explained by considering storm surges occur in Marseille about once every year on average. In this case GEV-BM is advantageous because the small number of events/year does not provide a more numerous calibration sample with respect to the sample of annual maxima. This result confirms the conclusion by Miniussi and Marani (2020), according to which the selection of the estimation window size for fitting the ordinary value distribution strongly depends on the average number of extreme events/year. 
https://doi.org/10.5194/nhess-2021-236

Preprint. Discussion started: 18 August 2021

(c) Author(s) 2021. CC BY 4.0 License.

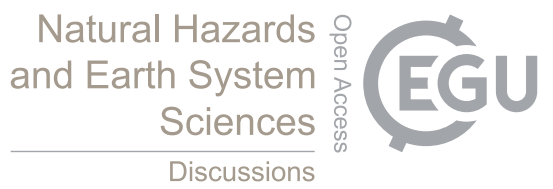

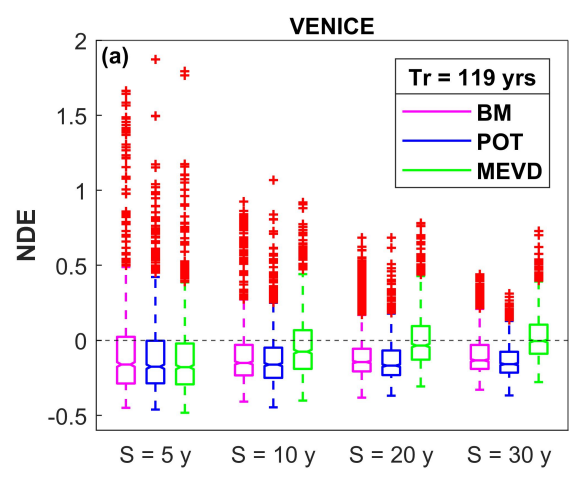
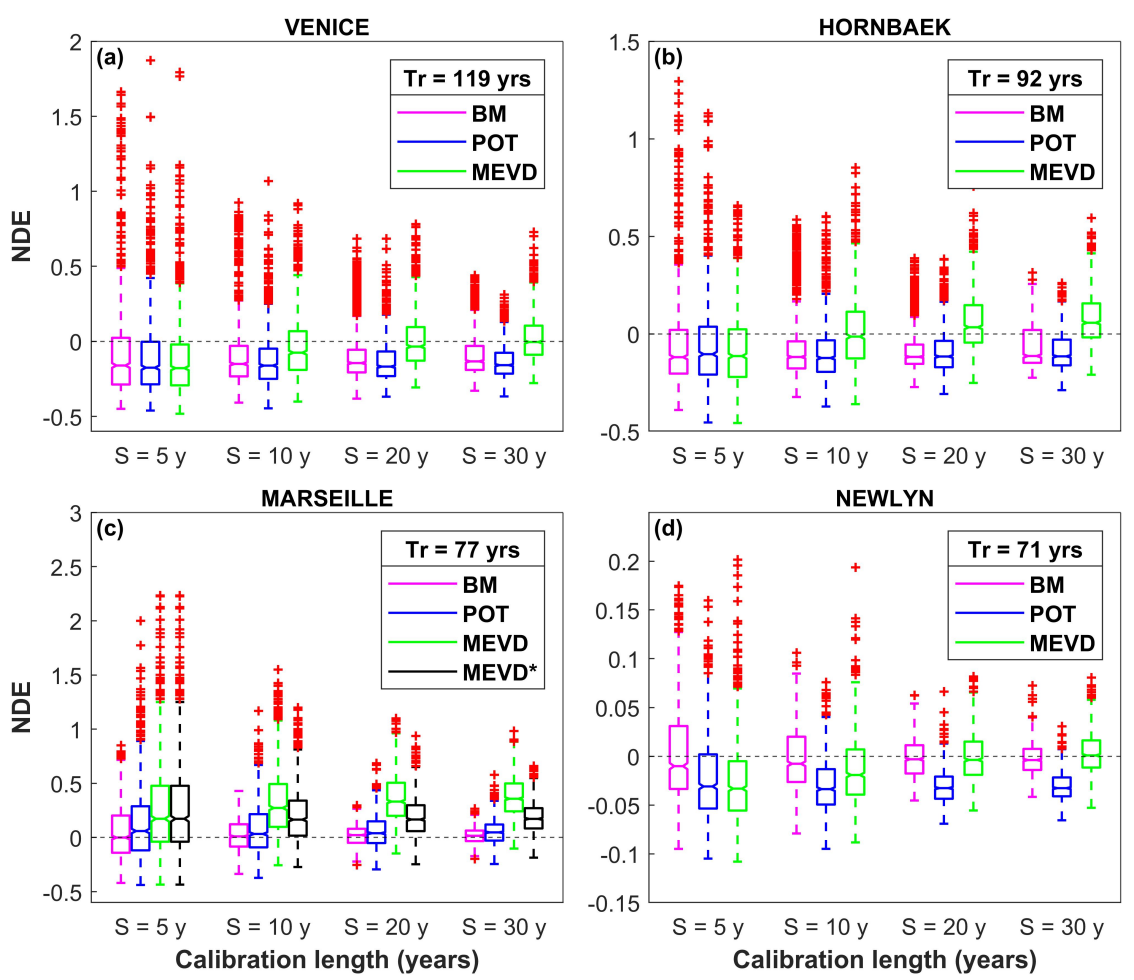

Figure 3. Distribution of the Non Dimensional Error (NDE) for maximum sample return period ( $T r$ ) represented by means of box-plots at given gauge stations explored: (a) Venice (IT), (b) Hornbæk (DK), (c) Marseille (FR), (d) Newlyn. In the case of the Marseille (FR) site, MEVD parameter estimation is based: 1) green colour: on non-overlapping sub-samples of fixed size (5 years), and 2) black colour: on data from the whole calibration sample. 
https://doi.org/10.5194/nhess-2021-236

Preprint. Discussion started: 18 August 2021

(c) Author(s) 2021. CC BY 4.0 License.
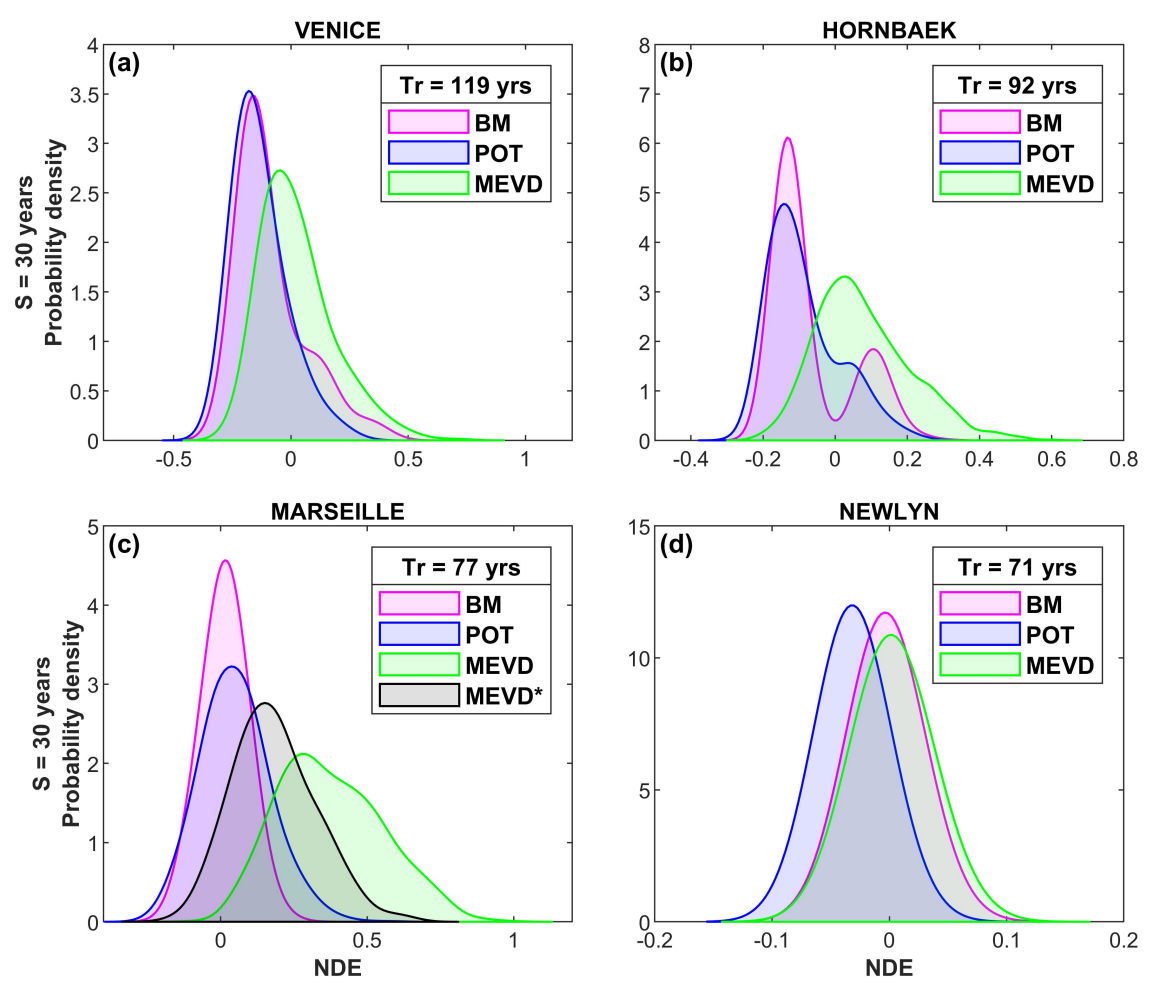

Figure 4. Kernel density estimates for the Non Dimensional Error (NDE) distributions obtained with a calibration sample size $(S)$ of 30 years and maximum return period (Tr) at given gauge stations explored: (a) Venice (IT), (b) Hornbæk (DK), (c) Marseille (FR), (d) Newlyn (UK). In the case of the Marseille (FR) site, MEVD parameter estimation is based: 1) green coluor: on non-overlapping sub-samples of fixed size (5 years), and 2) black colour: on data from the whole calibration sample. 


\subsection{Future projections of extreme storm surges}

We next explore how sea-level rise may influence the frequency of extreme storm surges across the sites analyzed. As described in $\S 2.2 .5$, we only evaluate the influence of an increased mean sea level, i.e. we do not address possible changes in storm regimes (e.g., see Tebaldi et al., 2012).

We use site-specific sea-level projections from IPCC's AR5 (Church et al., 2013), which indicate an accelerating sea-level rise at all four observation sites (for each gauge station under analysis, the reader can refer to the panels (a), (c), (e), and (g) in Figure 5), with expected water level increases at the end of the century (RCP8.5) of $48 \mathrm{~cm}$ in Venice, $52 \mathrm{~cm}$ in Hornbæk, $59 \mathrm{~cm}$ in Newlyn and $54 \mathrm{~cm}$ in Marseille. The panels (b), (d), (f), and (h) in Figure 5 show observed (green line) and future (blue and red lines) changes in the return period associated with event maximum water levels due to sea-level rise. These curves were obtained by using, in Eq. 4, the MEVD with parameters estimated on 5-year sliding windows. As noted above, changes in return levels are nonlinear way: relative changes are more significant for smaller extremes than for larger ones. The $\operatorname{Tr}$ vs. $z$ curves are concave downward and display varying slopes depending on the site explored. When a fixed return period is considered (e.g., 500 years), the mean sea level projections quantify the expected increase in extreme storm-surge level peaks for that particular return period. These changes vary heterogeneously across the different coastal sites explored. By comparing the percentage changes associated with the two emission scenarios and the two return periods (Table 4), Venice and Marseille are seen to experience the greatest changes in extreme water levels (e.g., with reference to $\operatorname{Tr}=100$ years and RCP8.5, the variations at Venice and Marseille sites are approximately 23\% and 39\% respectively). All sites display greater percent changes for the lower 100-year return period in each scenario, i.e. "less-infrequent" extremes will be most impacted by sea-level changes in the near future.

Changes in sea-level extremes can also be studied by focusing on changes in the return period of a fixed value of the water level. To this end, one can define a sensitivity measure as:

$S M=\frac{1}{T r} \cdot \frac{d T r}{d m s l}=-\frac{1}{T r} \cdot \frac{1}{[1-G(z-m s l)]^{2}} \cdot f(z-m s l)=-f(z-m s l) \cdot \operatorname{Tr}$

which is obtained by derivation of Eq. 4, and where $f(z)=\frac{d G}{d z}$ is the probability density function associated with $G(z)$. Eq. 5 shows that, at a given site and for a set value of $z$, the relative change in return period grows linearly with $\operatorname{Tr}$. For example, see in Figures 5b, d, f, h how, for a given value of $z$, changes (horizontal spacing between the curves) are greater for $\operatorname{Tr}=1000$ years than for $\operatorname{Tr}=500$ years. The expression for $S M$ also tells us that changes in $\operatorname{Tr}$ are more significant, everything else being equal, for values of $z-m s l$ near the mode of the distribution, where $f(z-m s l)$ is maximum (e.g., compare changes at the Venice or Hornbæk sites with those at Newlyn for a same initial value of $T r$ ).

\section{Conclusions}

In this study, we apply for the first time the Metastatistical Extreme Value Distribution to extreme sea levels observed at several sites along European coasts. Our analyses confirm practical and conceptual advantages of the MEVD with respect to traditional methods used for studying extreme events. 

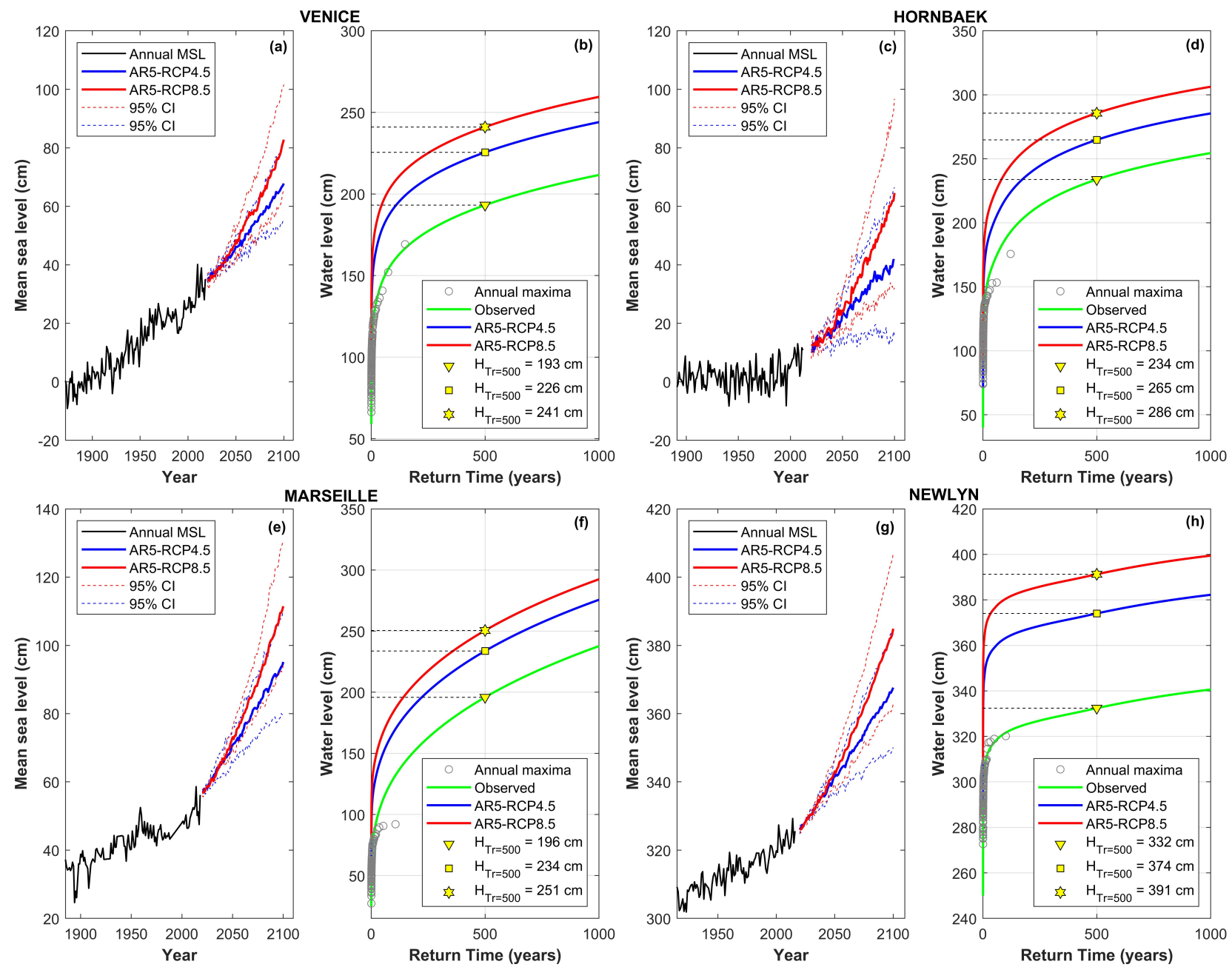

Figure 5. Future storm-surge projections at: Venice (IT, panels (a) and (b)), Hornbæk (DK, panels (c) and (d)), Marseille (FR, panels (e) and (f)), and Newlyn (UK, panels (g) and (h)). The panels represent: 1) (a), (c), (e), and (g): annual (black line) and future mean sea level until 2100 with RCP4.5 (blue line) and RCP8.5 (red line). Dashed line represents the 95\% confidence intervals. 2) (b), (d), (f), and (h): return period curves for extreme water level. The green curve represents the estimates obtained with the observed record; the blue and red curves represent the estimates obtained with the projected sea-level rise (SLR) until 2100 with RCP4.5 (blue) and RCP8.5 (red) respectively; the grey dots indicate the observed annual maxima. Triangle, square and pentagon highlight the heights of extreme storm surge for a fixed return period equal to 500 years. 
https://doi.org/10.5194/nhess-2021-236

Natural Hazards

Preprint. Discussion started: 18 August 2021

(c) Author(s) 2021. CC BY 4.0 License.

\section{Table 4.}

Results of the percentage changes in water level $(\Delta \mathrm{z})$ obtained with the two future scenarios (RCP4.5 and RCP8.5) and the return times (100 and 500 years) at the four sites under analysis.

\begin{tabular}{cccccc}
\hline \multirow{2}{*}{$\begin{array}{c}\operatorname{Tr} \\
\text { (yrs) }\end{array}$} & \multirow{2}{*}{ RCP } & \multicolumn{4}{c}{$\Delta \mathrm{z}(\%)$} \\
\cline { 3 - 6 } & & Venice & Hornbæk & Marseille & Newlyn \\
\hline \multirow{2}{*}{100} & 4.5 & $16.75 \%$ & $14.22 \%$ & $22.62 \%$ & $11.29 \%$ \\
& 8.5 & $22.82 \%$ & $21.76 \%$ & $29.73 \%$ & $15.26 \%$ \\
\hline \multirow{2}{*}{500} & 4.5 & $14.60 \%$ & $11.70 \%$ & $16.24 \%$ & $11.23 \%$ \\
& 8.5 & $19.92 \%$ & $18.18 \%$ & $21.91 \%$ & $15.09 \%$ \\
\hline
\end{tabular}

A cross-validation scheme (with 1,000 realizations for each sites) is used to compare model performances in high-quantile estimation. The use of two independent sub-sample (calibration and test sample) allows to quantify the "real" predictive uncertainty in the high-return period quantiles estimation. In this manner, it is possible to evaluate the capacity of the models to extrapolate from observed extremes and to predict the frequency of occurrence of unobserved ones.

To address the problems posed by observational samples of different sizes, we explored the effect on uncertainty of different calibration sample sizes, from 5 to 30 years. We find that MEVD approach provides reliable estimates of high quantiles in almost all the gauge stations explored, especially when we consider longer calibration sample sizes. Data from the Marseille gauge station exhibit a behaviour that deviates from those from other sites, showing an inferior predictive performance of MEVD with respect to GEV-based approaches. We interpret this fact to be linked to other factors (i.e. morphology, topography, bathymetry, tidal driven and atmosphere forcing), which result in a small number of large sea-level peaks every year. The small number of yearly ordinary events is such that the MEVD can use little additional information with respect to GEV-BM and GEV-POT.

Finally, we explore the variations of the frequency of extreme storm water levels under future sea-level scenarios. Analyses using sea-level projections through 2100 quantify the increase in extreme storm water levels associated with fixed values of the return period. Conversely, the return period of a fixed value of the water level decreases with increasing mean sea levels. The sensitivity of extreme water level frequency to sea-level rise is location-dependent, and the introduced sensitivity measure shows that, at a given site and for a set value of the water level, the relative change in return time grows linearly with the value of the latter.

The MEVD methodology proposed in this work, by relaxing some of the hypotheses underlying the traditional extreme value distribution, reduces the uncertainty associated with the assessment of coastal flooding risk under changing sea-levels. 
https://doi.org/10.5194/nhess-2021-236

Preprint. Discussion started: 18 August 2021

(c) Author(s) 2021. CC BY 4.0 License.

(c) (i)

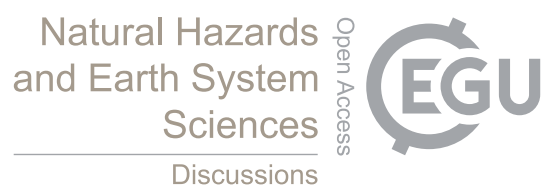

hawaii.edu/data/?rq\#uh745a/). The CMIP5 model outputs used for the future storm-surge projections are available at the "Integrated Climate Data Center" (ICDC) database of the University of Hamburg (https://icdc.cen.uni-hamburg.de/en/ar5-slr.html).

375 Competing interests. The authors declare that they have no conflict of interest.

Acknowledgements. M.F.C. acknowledges the PhD School in Civil Sciences and Environmental Engineering by University of Padova for funding her PhD. M.M. acknowledges financial support by the "Scientific activity performed with the contribution of the Provveditorato for the Public Works of Veneto, Trentino Alto Adige, and Friuli Venezia Giulia, provided through the concessionary of State Consorzio Venezia Nuova and coordinated by CORILA in the framework of the Venezia 2021 Research Program". 
https://doi.org/10.5194/nhess-2021-236

Preprint. Discussion started: 18 August 2021

(c) Author(s) 2021. CC BY 4.0 License.

\section{References}

Araújo, I. B. and Pugh, D. T.: Sea levels at Newlyn, 1915-2005: Analysis of trends for future flooding risks, J. Coastal Res., 24, 03-212, https://doi.org/10.2112/06-0785.1, 2008.

Balkema, A. A. and de Haan, L.: Residual life time at great age, Ann. Probab., 2, 792-804, https://doi.org/10.1214/aop/1176996548, 1974.

Barbariol, F., Bidlot, J.-R., Cavaleri, L., Sclavo, M., Thomson, J., and Benetazzo, A.: Maximum wave heights from global model reanalysis, Prog. Oceanogr., 175, 139-160, https://doi.org/10.1016/j.pocean.2019.03.009, 2019.

Beirlant, J., Goegebeur, Y., Segers, J. J. J., and Teugels, J.: Statistics of Extremes: Theory and Applications, John Wiley \& Sons, Chichester, UK, 2004.

Benetazzo, A., Ardhuin, F., Bergamasco, F., Cavaleri, L., Guimarães, P. V., Schwendeman, M., Sclavo, M., Thomson, J., and Torsello, A.: On the shape and likelihood of oceanic rogue waves, Sci. Rep, 7, 1-11, https://doi.org/10.1038/s41598-017-07704-9, 2017.

Bernardara, P., Andreewsky, M., and Benoit, M.: Application of regional frequency analysis to the estimation of extreme storm surges, J. Geophys. Res.-Oceans, 116, https://doi.org/10.1029/2010JC006229, 2011.

Bernardara, P., Mazas, F., Kergadallan, X., and Hamm, L.: A two-step framework for over-threshold modelling of environmental extremes, Nat. Hazard Earth Sys., 14, 635-647, https://doi.org/10.5194/nhess-14-635-2014, 2014.

Bernier, N. B. and Thompson, K. R.: Tide-surge interaction off the east coast of Canada and northeastern United States, J. Geophys. Res.Oceans, 112, https://doi.org/10.1029/2006JC003793, 2007.

Bommier, E.: Peaks-over-threshold modelling of environmental data, Master's thesis, Department of Mathematics, Uppsala University, 2014. Castillo, E., Hadi, A. S., Balakrishnan, N., and Sarabia, J. M.: Extreme Value and Related Models in Engineering and Science Applications, John Wiley \& Sons, New York, 2005.

Chiu, Y., Chebana, F., Abdous, B., Bélanger, D., and Gosselin, P.: Mortality and morbidity peaks modeling: an extreme value theory approach, Stat. Methods Med. Res., 27, 1498-1512, https://doi.org/10.1177/0962280216662494, 2018.

Chow, V. T.: Frequency analysis of hydrologic data with special application to rainfall intensities, University of Illinois Engineering Experiment Station, Bulletin 414, 1953.

Church, J. A. and White, N. J.: A 20th century acceleration in global sea-level rise, Surv. Geophys., 33, https://doi.org/10.1029/2005GL024826, 2006.

Church, J. A. and White, N. J.: Sea-Level Rise from the Late 19th to the Early 21st Century, Surv. Geophys., 32, https://doi.org/10.1007/s10712-011-9119-1, 2011.

Church, J. A., Clark, P. U., Cazenave, A., Gregory, J. M., Jevrejeva, S., Levermann, A., Merrifield, M. A., Milne, G. A., Nerem, R. S., Nunn, P. D., Payne, A. J., Pfeffer, W. T., Stammer, D., and Unnikrishnan, A. S.: Sea Level Change, in: Climate Change 2013: The Physical Science Basis. Contribution of Working Group I to the Fifth Assessment Report of the Intergovernmental Panel on Climate Change, edited by Stocker, T., Qin, D., Plattner, G.-K., Tignor, M., Allen, S., Boschung, J., Nauels, A., Xia, Y., Bex, V., and Midgley, P., chap. 13, pp. 1137-1216, Cambridge University Press, https://www.ipcc.ch/report/ar5/wg1/, 2013.

Cid, A., Menéndez, M., Castanedo, S., Abascal, A. J., Méndez, F. J., and Medina, R.: Long-term changes in the frequency, intensity and duration of extreme storm surge events in southern Europe, Clim. Dynam., 46, 1503-1516, https://doi.org/10.1007/s00382-015-2659-1, 2015.

415 Coles, S.: An Introduction to Statistical Modeling of Extreme Values, Springer, London, https://doi.org/10.1007/978-1-4471-3675-0, 2001. 
https://doi.org/10.5194/nhess-2021-236

Preprint. Discussion started: 18 August 2021

(c) Author(s) 2021. CC BY 4.0 License.

Coles, S. and Tawn, J.: Bayesian modelling of extreme surges on the UK east coast, Philos. T. Roy. Soc. A, 363, 1387-1406, https://doi.org/10.1098/rsta.2005.1574, 2005.

Dalrymple, T.: Flood frequency Analysis, Manual of hydrology: Part 3. Flood-flow techniques 1543, Geological Survey Water Supply Paper 1543-A, https://doi.org/10.3133/wsp1543A, 1960.

Davison, A. C. and Smith, R. L.: Models for Exceedances over High Thresholds, J. Roy. Stat. Soc. B-Met., 52, 393-442, http://www.jstor. org/stable/2345667, 1990.

De Zea Bermudez, P. and Mendes, Z.: Extreme value theory in medical sciences: modeling total high cholesterol levels, Journal of Statistical Theory and Practice volume, 6, 468-491, https://doi.org/10.1080/15598608.2012.695673, 2012.

Dixon, M. J. and Tawn, J. A.: The effect of non-stationarity on extreme sea-level estimation, J. Roy. Stat. Soc. C-App., 48, 135-151, 1999.

Eliot, M.: Influence of interannual tidal modulation on coastal flooding along the Western Australian coast, J. Geophys. Res.-Oceans, 115, https://doi.org/10.1029/2010JC006306, 2010.

Embrechts, P., Klüppelberg, C., and Mikosch, T.: Modelling Extremal Events for insurance and finance, Springer, New York, 1997.

Ferro, C. A. T. and Segers, J.: Inference for clusters of extreme values, J. Roy Stat. Soc. B-Met., 65, 545-556, https://doi.org/10.1111/14679868.00401, 2003.

Finkenstädt, B. and Rootzén, H.: Extreme Values in Finance, Telecommunications and the Environment, Taylor \& Francis Inc, Chapman \& Hall/CRC Monographs on Statistics \& Applied Probability, Boca Raton, Florida, 2004.

Fortunato, A. B., Li, K., Bertin, X., Rodrigues, M., and Miguez, B. M.: Determination of extreme sea levels along the Iberian Atlantic coast, Ocean Eng., 111, 471-482, https://doi.org/https://doi.org/10.1016/j.oceaneng.2015.11.031, 2016.

Fréchet, M. R.: Sur la loi de probabilité de l'écart maximum, Ann. Soc. Polon. Math., 6, 93-116, 1927.

Gnedenko, B. V.: Sur la distribution limite du terme maximum d'une serie aleatoire, Ann. Math., 44, 423-453, 1943.

Greenwood, J. A., Landwehr, J. M., Matalas, N. C., and Wallis, J. R.: Probability weighted moments: definition and relation to parameters of several distributions expressable in inverse form, Water Resour. Res., 15, 1049-1054, https://doi.org/10.1029/WR015i005p01049, 1979.

Gumbel, E. J.: Les valeurs extrêmes des distributions statistiques, Annales de l’Institut Henri Poincaré, 5, 115-158, www.numdam.org/item/ AIHP_1935_5_2_115_0/, 1935.

440 Gumbel, E. J.: Statistics of Extremes, Columbia University Press, New York, 1958.

Haigh, I. D., Nicholls, R., and Wells, N.: Assessing changes in extreme sea levels: Application to the English Channel, 1900-2006, Cont. Shelf. Res., 30, 1042-1055, https://doi.org/10.1016/j.csr.2010.02.002, 2010.

Haigh, I. D., Eliot, M., and Pattiaratchi, C.: Global influences of the 18.61-year nodal cycle and 8.85-year cycle of lunar perigee on high tidal levels, J. Geophys. Res.-Oceans, 116, 25 249, https://doi.org/10.1029/2010JC006645, 2011.

Haigh, I. D., MacPherson, L. R., Mason, M. S., Wijeratne, E. M. S., Pattiaratchi, C. B., Crompton, R. P., and George, S.: Estimating present day extreme water level exceedance probabilities around the coastline of Australia: tropical cyclone-induced storm surges, Clim. Dynam., 42, 139-157, https://doi.org/10.1007/s00382-012-1653-0, 2014a.

Haigh, I. D., Wahl, T., Rohling, E. J., Price, R. M., Pattiaratchi, C., Calafat, F. M., and Dangendorf, S.: Timescales for detecting a significant acceleration in sea level rise, Nat. Commun., 5, https://doi.org/10.1038/ncomms4635, 2014b.

450 Hall, T. M. and Sobel, A. H.: On the impact angle of Hurricane Sandy's New Jersey landfall, Geophys. Res. Lett., 40, 2312-2315, https://doi.org/10.1002/grl.50395, 2013.

Hamdi, Y., Bardet, L., Duluc, C.-M., and Rebour, V.: Extreme storm surges: a comparative study of frequency analysis approaches, Nat. Hazard Earth Sys., 14, 2053-2067, https://doi.org/10.5194/nhess-14-2053-2014, 2014. 
https://doi.org/10.5194/nhess-2021-236

Preprint. Discussion started: 18 August 2021

(c) Author(s) 2021. CC BY 4.0 License.

Hamdi, Y., Bardet, L., Duluc, C.-M., and Rebour, V.: Use of historical information in extreme-surge frequency estimation: the case of marine flooding on the La Rochelle site in France, Nat. Hazard Earth Sys., 15, 1515-1531, https://doi.org/10.5194/nhess-15-1515-2015, 2015.

Hamdi, Y., Garnier, E., Giloy, N., Duluc, C.-M., and Rebour, V.: Analysis of the risk associated with coastal flooding hazards: a new historical extreme storm surges dataset for Dunkirk, France, Nat. Hazard Earth Sys., 18, 3383-3402, https://doi.org/10.5194/nhess-18-3383-2018, 2018.

Hay, C., Morrow, E., Kopp, R., and Mitrovica, J. X.: Probabilistic reanalysis of twentieth-century sea-level rise, Nature, 517, 481-484, https://doi.org/10.1038/nature14093, 2015.

Hosking, J. R. M.: L-moments: Analysis and estimation of distributions using linear combinations of order statistics, J. Roy. Stat. Soc. B-Met., 52, 105-124, 1990.

Hosking, J. R. M. and Wallis, J. R.: Parameter and Quantile Estimation for the Generalized Pareto Distribution, Technometrics, 29, 339-349, http://www.jstor.org/stable/1269343, 1987.

Hosking, J. R. M. and Wallis, J. R.: Some statistics useful in regional frequency analysis, Water Resour. Res., 29, 271-281, https://doi.org/10.1029/92WR01980, 1993.

Hosking, J. R. M. and Wallis, J. R.: Regional frequency analysis: an approach based on L-moments, Cambridge University press, https://doi.org/10.1017/CBO9780511529443, 1997.

Hosking, J. R. M., Wallis, J. R., and Wood, E. F.: Estimation of the generalized extreme-value distribution by the method of probabilityweighted moments, Technometrics, 27, 251-261, https://doi.org/10.1080/00401706.1985.10488049, 1985.

Hosseini, S. R., Scaioni, M., and Marani, M.: Extreme Atlantic hurricane probability of occurrence through the Metastatistical Extreme Value Distribution, Geophys. Res. Lett., 47, 2019GL086 138, https://doi.org/10.1029/2019GL086138, 2020.

Jevrejeva, S., Moore, J. C., Grinsted, A., and Woodworth, P. L.: Recent global sea level acceleration started over 200 years ago?, Geophys. Res. Lett., 35, https://doi.org/10.1029/2008GL033611, 2008.

Johns, B. and Ali, M. A.: The numerical modeling of storm surges in the Bay of Bengal, Q. J. Roy. Meteor. Soc., 106, 1-18, https://doi.org/10.1002/qj.49710644702, 1980.

Katz, R. W., Parlange, M. B., and Naveau, P.: Statistics of extremes in hydrology, Adv. Water Resour., 25, 1287-1304, https://doi.org/10.1016/S0309-1708(02)00056-8, 2002.

Katz, R. W., Brush, G. S., and Parlange, M. B.: Statistics of extremes: modeling ecological disturbances, Ecology, Ecology, 86, 1124-1134, https://doi.org/10.1890/04-0606, 2005.

Li, G., Zhang, X., Zwiers, F., and Wen, Q. H.: Quantification of uncertainty in high-resolution temperature scenarios for North America, J. Climate, 25, 3373-3389, https://doi.org/10.1175/JCLI-D-11-00217.1, 2012.

Lionello, P., Sanna, A., Elvini, E., and Mufato, R.: A data assimilation procedure for operational prediction of storm surge in the northern Adriatic Sea, Cont. Shelf. Res., 26, 539-5539, https://doi.org/10.1016/j.csr.2006.01.003, 2006.

Lowe, J. A., Woodworth, P. L., Knutson, T., McDonald, R. E., McInnes, K., Woth, K., Von Storch, H., Wolf, J., Swail, V., Bernier, N., Gulev, S., Horsburgh, K., Unnikrishnan, A. S., Hunter, J., and Weisse, R.: Past and future changes in extreme sea levels and waves, in: Understanding Sea-Level Rise and Variability, edited by Church, J. A., Woodworth, P. L., Aarup, T., and Wilson, W. S., chap. 11, pp. 326-375, Wiley-Blackwell, https://doi.org/10.1002/9781444323276, 2010.

Mann, H. B.: Nonparametric Tests Against Trend, Econometrica, 13, 245-259, 1945.

490 Marani, M. and Ignaccolo, M.: A metastatistical approach to rainfall extremes, Adv. Water Resour., 79, 121-126, https://doi.org/https://doi.org/10.1016/j.advwatres.2015.03.001, 2015. 
https://doi.org/10.5194/nhess-2021-236

Preprint. Discussion started: 18 August 2021

(c) Author(s) 2021. CC BY 4.0 License.

Marra, F., Nikolopoulos, E. I., Anagnostou, E. N., and Morin, E.: Metastatistical extreme value analysis of hourly rainfall from short records: Estimation of high quantiles and impact of measurement errors, Adv. Water Resour., 117, 27-39, https://doi.org/https://doi.org/10.1016/j.advwatres.2018.05.001, 2018.

McInnes, K. L., Hubbert, G., Macadam, I., and O’Grady, J.: An assessment of current and future vulnerability to coastal inundation due to sea-level extremes in Victoria, southeast Australia, Int. J. Climatol., 33, 33-47, https://doi.org/10.1002/JOC.3405, 2013.

Meehl, G., Stocker, T., Collins, W. D., Friedlingstein, P., Gaye, A., Gregory, J. M., Kitoh, A., Knutti, R., Murphy, J. M., Noda, A., Raper, S. C. B., Watterson, I. G., Weaver, A. J., and Zhao, Z. C.: Global Climate Projections, in: Climate Change 2007: The Physical Science Basis. Contribution of Working Group I to the Fourth Assessment Report of the Intergovernmental Panel on Climate Change, edited by Solomon, S., Qin, D., Manning, M., Chen, Z., Marquis, M., Averyt, K., Tignor, M., and Miller, H., chap. 10, pp. 747846, Cambridge University Press, http://www.ipcc.ch/publications_and_data/publications_ipcc_fourth_assessment_report_wg1_report_ the_physical_science_basis.htm, 2007.

Menéndez, M. and Woodworth, P. L.: Changes in extreme high water levels based on a quasi-global tide-gauge data set, J. Geophys. Res., 115, 1124-1134, https://doi.org/10.1029/2009JC005997, 2010.

Miniussi, A. and Marani, M.: Estimation of Daily Rainfall Extremes Through the Metastatistical Extreme Value Distribution: Uncertainty Minimization and Implications for Trend Detection, Water Resour. Res., 56, e2019WR026 535, https://doi.org/0.1029/2019WR026535, 2020.

Miniussi, A., Marani, M., and Villarini, G.: Metastatistical Extreme Value Distribution applied to floods across the continental United States, Adv. Water Resour., 136, 103 498, https://doi.org/10.1016/j.advwatres.2019.103498, 2020a.

510 Miniussi, A., Villarini, G., and Marani, M.: Analyses through the metastatistical extreme value distribution identify contributions of tropical cyclones to rainfall extremes in the eastern United States, Geophys. Res. Lett., 47, e2020GL087238, https://doi.org/10.1029/2020GL087238, 2020b.

Önöz, B. and Bayazit, M.: Effect of the occurrence process of the peaks over threshold on the flood estimates, J. Hydrol., 244, 86-96, https://doi.org/10.1016/S0022-1694(01)00330-4, 2001.

Oppenheimer, M., Glavovic, B., Hinkel, J., van de Wal, R., Magnan, A., Abd-Elgawad, A., Cai, R., Cifuentes-Jara, M., DeConto, R., Ghosh, T., Hay, J., Isla, F., Marzeion, B., Meyssignac, B., and Sebesvari, Z.: Sea Level Rise and Implications for Low-Lying Islands, Coasts and Communities, in: IPCC Special Report on the Ocean and Cryosphere in a Changing Climate, edited by Pörtner, H.-O., Roberts, D., Masson-Delmotte, V., Zhai, P., Tignor, M., Poloczanska, E., Mintenbeck, K., Alegría, A., Nicolai, M., Okem, A., Petzold, J., Rama, B., and Weyer, N. M., chap. 4, pp. 321-445, Cambridge University Press, https://www.ipcc.ch/srocc/download-report/, 2019.

Peng, D., Hill, E. M., and Meltzner, A. J.and Switzer, A. D.: Tide gauge records show that the 18.61-year nodal tidal cycle can change high water levels by up to 30 cm, J. Geophys. Res.-Oceans, 124, 736-749, https://doi.org/10.1029/2018JC014695, 2019.

Pickands, III, J.: Statistical inference using extreme order statistics, Ann. Stat., 3, 119-131, https://doi.org/10.1214/aos/1176343003, 1975.

Pisarenko, V. F., Rodkin, M. V., and Rukavishnikova, T. A.: Estimation of the probability of strongest seismic disasters based on the extreme value theory, Izvestiya, Physics of the Solid Earth, 50, 311-324, https://doi.org/10.1134/S1069351314030070, 2014a.

Pisarenko, V. F., Sornette, A., Sornette, D., and Rodkin, M. V.: Characterization of the Tail of the Distribution of Earthquake Magnitudes by Combining the GEV and GPD Descriptions of Extreme Value Theory, Pure Appl. Geophys., 171, 1599-1624, https://doi.org/10.1007/s00024-014-0882-z, 2014b.

Pugh, D. T. and Vassie, J. M.: Extreme sea levels from tide and surge probability, in: Proc. 16th International Conference on Coastal Engineering 1978, Hamburg, Germany, chap. 52, pp. 911-930, American Society of Civil Engineers, 1979. 
https://doi.org/10.5194/nhess-2021-236

Preprint. Discussion started: 18 August 2021

(c) Author(s) 2021. CC BY 4.0 License.

(c) (i)

Pugh, D. T. and Woodworth, P. L.: Sea-Level Science: Understanding Tides, Surges, Tsunamis and Mean Sea-Level Changes, Cambridge University Press, 2014.

Rueda, A., Camus, P., Méndez, F. J., Tomás, A., and Luceño, A.: An extreme value model for maximum wave heights based on weather types, J. Geophys. Res.-Oceans, 121, 1262-1273, https://doi.org/10.1002/2015JC010952, 2016.

Schellander, H., Lieb, A., and Hell, T.: Error structure of metastatistical and generalized extreme value distributions for modeling extreme rainfall in Austria, Earth and Space Science, 6, 1616-1632, https://doi.org/10.1029/2019EA000557, 2019.

Songchitruksa, P. and Tarko, A. P.: The extreme value theory approach to safety estimation, Accident Anal. Prev., 38, 811-822, https://doi.org/10.1016/j.aap.2006.02.003, 2006.

Tebaldi, C., Strauss, B. H., and Zervas, C. E.: Modelling sea level rise impacts on storm surges along US coasts, Environ. Res. Lett., 7, 014-032, https://doi.org/10.1088/1748-9326/7/1/014032, 2012.

540 Valle-Levinson, A., Marani, M., Carniello, L., D’Alpaos, A., and Lanzoni, S.: Astronomic link to anomalously high mean sea level in the northern Adriatic Sea, Estuar. Coast. Shelf. S., 257, 107418, https://doi.org/10.1016/j.ecss.2021.107418, 2021.

Volpi, E., Fiori, A., Grimaldi, S., Lombardo, F., and Koutsoyiannis, D.: Save hydrological observations! Return period estimation without data decimation, J. Hydrol., 571, 782-792, https://doi.org/10.1016/j.jhydrol.2019.02.017, 2019.

Von Mises, R.: La distribution de la plus grande de n valuers, Rev. math. Union interbalcanique, 1, 141-160, 1936.

545 Vousdoukas, M. I., Voukouvalas, E., Annunziato, A., Giardino, A., and Feyen, L.: Projections of extreme storm surge levels along Europe, Clim. Dynam., 47, 3171-3190, https://doi.org/10.1007/s00382-016-3019-5, 2016.

Woodworth, P. L. and Blackman, D. L.: Changes in high waters at Liverpool since 1768, Int. J. Climatol., 22, 697-7147, https://doi.org/https://doi.org/10.1002/joc.761, 2002.

Woodworth, P. L. and Blackman, D. L.: Evidence for systematic changes in extreme high waters since the mid-1970s, J. Climate, 17, 1190-1197, https://doi.org/10.1175/1520-0442(2004)017<1190:EFSCIE>2.0.CO;2, 2004.

Woodworth, P. L., Menéndez, M., and Roland Gehrels, W.: Evidence for Century-Timescale Acceleration in Mean Sea Levels and for Recent Changes in Extreme Sea Levels, Surv. Geophys., 32, 603-618, https://doi.org/10.1007/s10712-011-9112-8, 2011.

Zhang, K., Douglas, B. C., and Leatherman, S. P.: Twentieth-century storm activity along the U.S. east coast, J. Climate, 13, 1748-1761, https://doi.org/10.1175/1520-0442(2000)013<1748:TCSAAT>2.0.CO;2, 2000.

Zhang, W.-Z., Shi, F., Hong, H.-S., Shang, S.-P., and Kirby, J. T.: Tide-surge interaction intensified by the Taiwan Strait, J. Geophys. Res.Oceans, 115, https://doi.org/10.1029/2009JC005762, 2010.

Zorzetto, E. and Marani, M.: Downscaling of rainfall extremes from satellite observations, Water Resour. Res., 55, 156-174, https://doi.org/10.1029/2018WR022950, 2019.

Zorzetto, E. and Marani, M.: Extreme value metastatistical analysis of remotely sensed rainfall in ungauged areas: Spatial downscaling and error modelling, Adv. Water Resour., 135, 103 483, https://doi.org/10.1016/j.advwatres.2019.103483, 2020.

Zorzetto, E., Botter, G., and Marani, M.: On the emergence of rainfall extremes from ordinary events, Geophys. Res. Lett., 43, 8076-8082, https://doi.org/10.1002/2016GL069445, 2016. 